\title{
CARACTERIZAÇÃO DE UMA ZONA COSTEIRA TROPICAL (IPOJUCA- PERNAMBUCO-BRASIL): PRODUTIVIDADE FITOPLANCTÔNICA E OUTRAS VARIÁVEIS AMBIENTAIS.
}

\author{
BASTOS, R. B. ${ }^{1,2^{*}}$; FEITOSA, F. A. N. ${ }^{1}$; KOENING, M. L. ${ }^{1}$; MACHADO, R. C. A. ${ }^{1}$ \& MUNIZ, K. ${ }^{3}$ \\ 1 - Universidade Federal de Pernambuco, Departamento de Oceanografia, Laboratório de \\ Fitoplâncton. Avenida Arquitetura, s/n CEP: 50610-901, Recife - PE. Brasil. \\ 2 - Doutoranda do Programa de Pós-Graduação em Oceanografia da UFPE. Bolsista CAPES. \\ 3 - Universidade Federal de Pernambuco, Departamento de Oceanografia, Laboratório de Oceano- \\ grafia Química. Avenida Arquitetura, s/n CEP: 50610-901, Recife - PE. Brasil. \\ * Corresponding author: rafaellabb@hotmail.com
}

\begin{abstract}
BASTOS, R. B.; FEITOSA, F. A. N.; KOENING, M. L.; MACHADO, R. C. A. \& MUNIZ, K. 2011. Characterization of a tropical coastal zone (Ipojuca, Pernambuco, Brazil): Phytoplanktonic production and other environmental variables. Braz. J. Aquat. Sci. Technol. 15(1): 01-10. ISSN 1983-9057. The coastal area of Maracaípe is sited 60km south of Recife, at Ipojuca (Pernambuco, Brazil), and stands out on the state coast for showing two of the most productive ecosystems: reef and estuary. The objective of this study was to diagnose the current status of these ecosystems considering phytoplankton biomass (chlorophyll a) and productivity $\left(\mathrm{C}^{14}\right)$, and some environmental variables such as depth, water transparency, temperature, salinity, dissolved oxygen, nutrient salts, $\mathrm{pH}$ and particulate suspended material. Samples were collected from the surface at six sites during high and low daytime spring tides on three months during each season, rainy and dry. Salinity varied from 1 to 37 , oxygen saturation from 56.78 to $173.82 \%$, nitrite and phosphate were less than $1 \mu \mathrm{mol} . \mathrm{L}^{-1}$, nitrate was $<3.5 \mu \mathrm{mol} . \mathrm{L}^{-1}$ and silicate varied from 11.71 to $92.26 \mu \mathrm{mol} . \mathrm{L}^{-1}$; biomass ranged from 1.11 to $18.72 \mathrm{mg} \cdot \mathrm{m}^{-3}$ and productivity from 4.62 to $75.27 \mathrm{mgC} \cdot \mathrm{m}^{-3} \cdot \mathrm{h}^{-1}$. According to Principal Components Analysis (PCA) results, there was high positive correlation between tides, depth, transparency, salinity and dissolved $\mathrm{O}_{2}$, and inverse correlation to silicate, chlorophyll a, productivity and assimilation rate; also, the pluviometry was directly correlated to nitrite, nitrate and phosphate and inversely to temperature. The environment showed to be homogeneous, that is, without thermal and saline stratification, varying from oligohaline to euhaline and predominantly supersaturated throughout the study, typical of unpolluted areas, and the trophic rate varied from oligotrophic to eutrophic. The studied coastal area was characterized by clear and warm waters with no influence of domestic or industrial effluents.
\end{abstract}

Keywords: chlorophyll a, hydrology, estuary, reefs, Maracaípe.

\section{INTRODUÇÃO}

As áreas costeiras são as mais ricas dos oceanos e respondem por mais da metade da sua produtividade sendo responsável por quase o total da pesca mundial. Ao longo dos litorais, sais nutrientes são retirados do continente, ventos de superfície e correntes marítimas dragam sedimentos ricos nestes sais, e a luz solar favorece o crescimento de organismos fotossintetizantes (Corson, 2002).

Em conseqüência da entrada constante dos nutrientes de origem continental, as águas costeiras tendem a não apresentar exaustão total destes sais, mesmo nos trópicos (Pereira \& Soares-Gomes, 2002). Elevadas taxas no ambiente costeiro freqüentemente induzem o crescimento da biomassa fitoplanctônica, aumentando assim, a quantidade de matéria orgânica e resultando numa eutrofização (Nixon, 1995; Smith et al., 1999).

As algas planctônicas possuem um grande significado ecológico, por constituírem o inicio da teia trófica, e também por responderem rapidamente aos impactos ambientais, sendo desta forma excelentes indicadores da qualidade da água (Eskinazi-Leça et al., 2002). A ação dos fatores ambientais reflete diretamente na estrutura da comunidade, condicionando o estabelecimento da mesma, que se encontra adaptada às oscilações destas variáveis (Silva-Cunha, 2001).

Os ecossistemas aquáticos vêm sendo gradativamente destruídos pelo constante lançamento nas bacias hidrográficas de efluentes industriais e urbanos, assim como pela expansão imobiliária, em decorrência do desenvolvimento desordenado das cidades (GESAMP, 1995). Na medida em que ocorrem mudanças nas condições ecológicas os habitats se alteram, causando perda da biodiversidade. Estas mudanças nos habitats ou nas abundâncias das espécies marinhas estão associadas, geralmente a impactos antropogênicos, principalmente em áreas costeiras sujeitas a múltiplos usos indiscriminados (Costa et al., 2004).

A praia de Maracaípe se destaca no litoral pernambucano por apresentar águas transparentes e quentes, e ainda por possuir os ecossistemas costei- 
ros mais produtivos, que são o recifal e o estuarino. Por sua vez este estuário vem sofrendo um grave processo erosivo, provocado por agentes naturais, tendo sido acelerado por intervenções antrópicas, como desmatamento e aterro do mangue, construção de espigões e retificação da margem direita do mesmo, onde foi feito um enrocamento para evitar a erosão (CPRH, 1998).

Este trabalho teve como objetivo diagnosticar a atual situação dos ecossistemas recifal e estuarino, levando-se em conta a produtividade fitoplanctônica e algumas variáveis ambientais, assim como o nível de interação e interdependência entre estes ecossistemas.

\section{ÁREA ESTUDADA}

O clima da área estudada, segundo a classificação de Köppen é do tipo Ams' e caracteriza-se por apresentar chuvas de outono-inverno durante quase todo o ano, porém com uma estação de estiagem (setembro a fevereiro) e chuvosa (março a agosto) bem definida e relativamente curta. É considerado um clima quente e úmido, com precipitação média anual de $2.050 \mathrm{~mm}$, enquanto que a temperatura varia entre 24 e $32^{\circ} \mathrm{C}$ (Chaves, 1991).

Segundo Manso et al. (2003) um dos traços morfológicos mais característicos do litoral pernambucano é a presença constante, na plataforma continental interna, de linhas de arenito (beachrocks) geralmente paralela à costa, servindo de substrato para o desenvolvimento de algas, corais e outros organismos, constituindo uma efetiva proteção ao litoral.

A porção estuarina do rio Maracaípe localiza-se no litoral sul do estado de Pernambuco $\left(8^{\circ} 31^{\prime} 00^{\prime \prime}\right.$ Lat. S e $34^{\circ} 59^{\prime} 30^{\prime \prime}$ Long. W). Este rio é considerado litorâneo e se estende paralelamente à costa, estreito com cerca de $13 \mathrm{~km}$ de extensão, e possui margens formadas por manguezais, restinga e coqueirais ( $\mathrm{CPRH}, 2003$; Andrade et al. 2004).

\section{MATERIAL E MÉTODOS}

As coletas foram realizadas no período de estiagem (janeiro, fevereiro e março/06) e no chuvoso (junho, julho e agosto/06) em seis pontos fixos, na superfície, durante a baixa-mar e preamar de um mesmo dia, em maré de sizígia. Para tais coletas utilizou-se garrafa de Van Dorn.

Baseado nas características hidrográficas estabeleceu-se seis pontos fixos de amostragens nas zonas estuarina e recifal assim distribuídos: Ponto 1 na desembocadura do rio Maracaípe $0 \mathrm{~km}$ da costa; Ponto 2 próximo à desembocadura do rio Maracaípe $0,70 \mathrm{~km}$ do $\mathrm{P} 1$; Ponto 3 na porção intermediária do rio Maracaípe 1,50km do P1; Ponto 4 na porção interna do rio Maracaípe 2,00km do P1; Ponto 5 na parte interna do recife $0,53 \mathrm{~km}$ ao norte do $P 1$ e Ponto 6 na parte interna do recife $0,50 \mathrm{~km}$ ao sul do P1 (Figura 1).

Os dados pluviométricos foram adquiridos através da Estação Meteorológica de Porto de Galinhas, pertencente ao Instituto de Pesquisas Agropecuárias (IPA), distante cerca de $3 \mathrm{~km}$ da área estudada; a profundidade local foi medida através de uma ecossonda manual digital LCD da Echotest; a transparência através do disco de Secchi; a temperatura com o uso de um termômetro comum com escala entre -10 e $60^{\circ} \mathrm{C}$; a salinidade por intermédio de um refratômetro manual da Atago; o pH foi determinado por um pH-metro Beckmam Zeromatic Il; a concentração de oxigênio pelo método de Winkler modificado e descrito por Strickland \& Parsons (1972). A taxa de saturação foi calculada correlacionando-se os dados de temperatura e salinidade usando-se a Tabela da UNESCO (1973). As concentrações de nitrito, nitrato e fosfato através do método de Strickland \& Parsons (1972), e para análise do silicato o método de Grasshoff et al. (1983). O material particulado em suspensão pelo método de Melo et al. (1975).

A biomassa fitoplanctônica foi obtida através do método espectrofotométrico da UNESCO (1966), sendo expressa em mg.m ${ }^{-3}$. Para a produtividade fitoplanctônica foram feitas coletas nos pontos P1, P2, P4, P5 e P6 na baixa-mar, utilizando-se o método $C^{14}$ de Steemann-Nielsen (1952), com 3 horas de incubação in situ, sendo a leitura dos filtros processada no cintilador líquido Tricarb 1600 A da Packard do Instituto Oceanográfico de São Paulo. Os cálculos foram baseados em Teixeira (1973), sendo expressos em mgC.m${ }^{3} \cdot \mathrm{h}^{-1}$. A taxa de assimilação do fitoplâncton baseada em Vollenweider et al. (1974).

A análise de componentes principais foi baseada na matriz de correlação momento-produto de Pearson de acordo com Legendre \& Legendre (1984), e o programa computacional foi o NTSYS. Foi utilizado o teste de Kruskall-Wallis, levando-se em consideração o nível de significância $<0,05$ para testar diferenças de sazonalidade, espacialidade e marés.

\section{RESULTADOS}

O total de chuvas precipitado em 2006 foi de $1639 \mathrm{~mm}$ estando próximo da média histórica de 15 anos, havendo apenas uma diferença de $122 \mathrm{~mm}$ para menos. A distribuição mensal das chuvas no ano de 2006 acompanhou o da média histórica, destacandose apenas os meses de abril, maio, junho e dezembro que estiveram acima dessa média. O mínimo registra- 


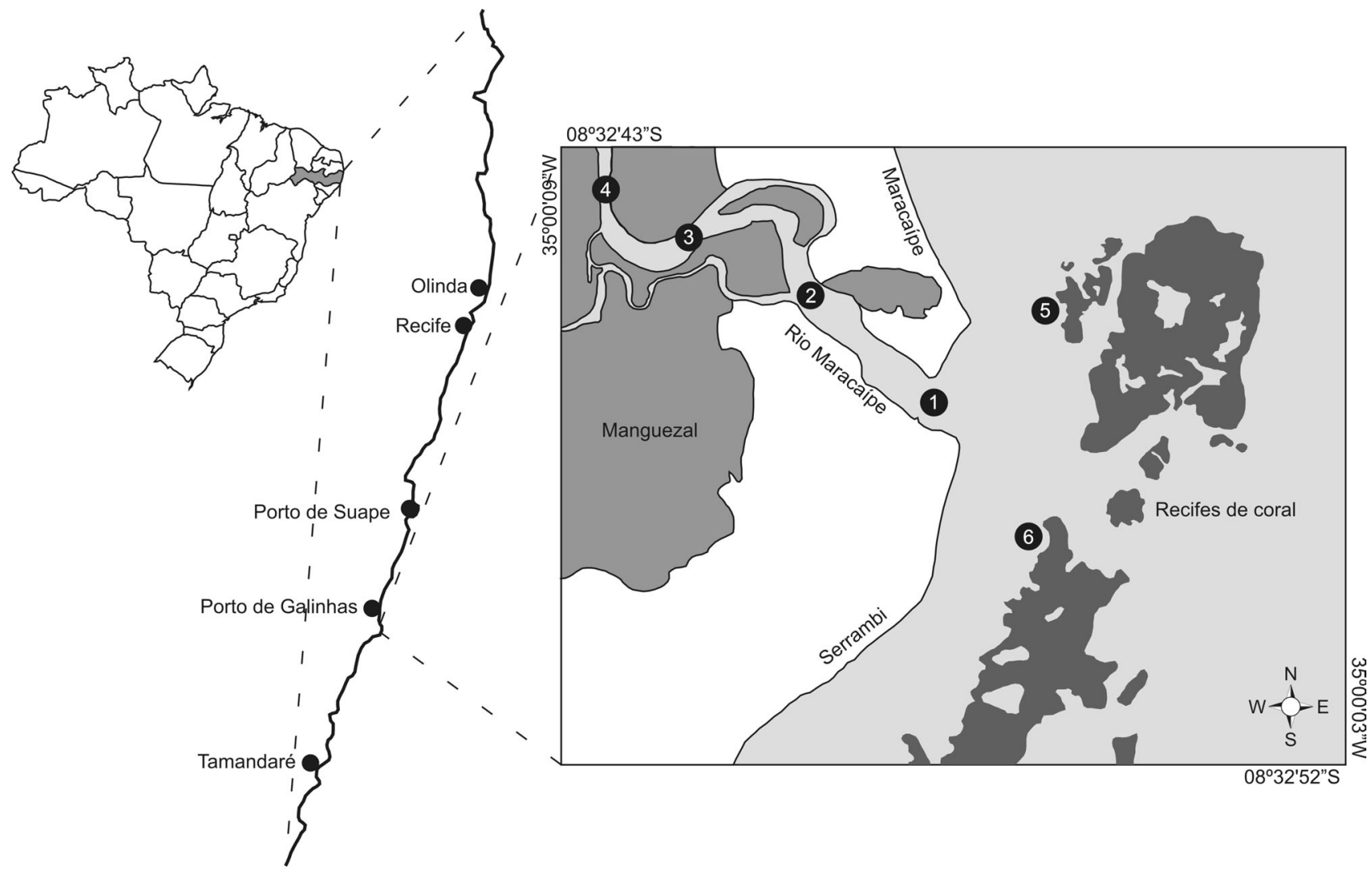

Figura 1 - Localização dos pontos de coleta na zona costeira de Maracaípe, PE, Brasil. (Fonte: Google Earth, 2009).

do foi de $4 \mathrm{~mm}$ em outubro e o máximo de $415 \mathrm{~mm}$ em junho (Tabela 1).

O ambiente estudado de forma geral é considerado raso, variando em função da topografia do sedimento e da amplitude de maré. A profundidade mínima encontrada foi de $0,25 \mathrm{~m}$ no ponto 6 , em fevereiro, durante a baixa-mar, e a máxima foi de $2,70 \mathrm{~m}$ no ponto 2 , em janeiro, na preamar (Tabela 1).

O ambiente caracterizou-se por apresentar alta transparência da água, coincidindo durante vários meses com a profundidade local, principalmente no período de estiagem com exceção do ponto 2 em janeiro durante a baixa-mar. Já durante o período chuvoso houve uma redução da transparência, principalmente nos pontos estuarinos (P1, P2, P3 e P4). A transparência mínima obtida foi de $0,25 \mathrm{~m}$ no ponto 6 em fevereiro durante a baixa-mar, e a máxima foi de $2,70 \mathrm{~m}$ no ponto 2 em janeiro, durante a preamar (Tabela 1 ).

A temperatura da água variou sazonalmente com menores valores no período chuvoso. A temperatura no ponto 6 esteve diferente das demais nos meses de março e junho quando esteve mais elevada. Não se observou estratificação térmica possivelmente em função da baixa profundidade e da dinâmica local. A tem-

Tabela 1 - Variáveis biológicas e abióticas nos períodos de estiagem e chuvoso (Min. = mínimo, Máx. = máximo, média e DP = desvio padrão) e teste de Kruskal-Wallis com valores do p para os diferentes tratamentos (sazonal, espacial e tidal).

\begin{tabular}{|c|c|c|c|c|c|c|c|c|c|c|c|}
\hline \multirow{2}{*}{ PARÂMETROS } & \multicolumn{4}{|c|}{ ESTIAGEM } & \multicolumn{4}{|c|}{ CHUVOSO } & \multicolumn{3}{|c|}{ TESTE KRUSKAL -WALLIS (p) } \\
\hline & Mín. & Máx. & Média & DP & Mín. & Máx. & Média & DP & Sazonal & Espacial & Tidal \\
\hline Pluviosidade $2006(\mathrm{~mm})$ & 4,00 & 55,00 & 34,50 & $\pm 20,01$ & 84,00 & 415,00 & 238,67 & $\pm 141,12$ & 0,02 & - & - \\
\hline Pluviosidade Média Histórica (mm) & 36,00 & 91,00 & 63,50 & - & 139,00 & 370,00 & 230,30 & - & - & - & - \\
\hline Profundidade $(\mathrm{m})$ & 0,25 & 2,70 & 1,43 & $\pm 0,73$ & 0,30 & 2,60 & 1,34 & $\pm 0,57$ & 0,57 & 0,17 & 0,00 \\
\hline Transparência (m) & 0,25 & 2,70 & 1,44 & $\pm 0,73$ & 0,30 & 1,60 & 0,89 & $\pm 0,36$ & 0,00 & 0,83 & 0,00 \\
\hline Temperatura $\left({ }^{\circ} \mathrm{C}\right)$ & 27,00 & 31,40 & 29,90 & $\pm 0,93$ & 26,00 & 29,00 & 26,80 & $\pm 0,64$ & 0,00 & 0,12 & 0,94 \\
\hline Salinidade & 20,00 & 37,00 & 34,30 & $\pm 3,92$ & 1,00 & 37,00 & 23,90 & $\pm 14,35$ & 0,00 & 0,00 & 0,00 \\
\hline Conc. $\mathrm{O}_{2}\left(\mathrm{ml} . \mathrm{L}^{-1}\right)$ & 3,54 & 7,37 & 5,34 & $\pm 0,93$ & 3,14 & 6,24 & 4,55 & $\pm 0,87$ & 0,00 & 0,00 & 0,00 \\
\hline Tx. Sat. ${ }_{2}(\%)$ & 74,84 & 173,82 & 123,64 & $\pm 24,21$ & 56,78 & 134,19 & 96,01 & $\pm 24,45$ & 0,00 & 0,00 & 0,00 \\
\hline Mat.Suspensão (m g. $\left.\mathrm{L}^{-1}\right)$ & 2,20 & 69,00 & 9,18 & $\pm 11,03$ & 2,20 & 30,00 & 15,02 & $\pm 7,41$ & 0,00 & 0,44 & 0,04 \\
\hline Nitrito $\left(\mu \mathrm{mol} . \mathrm{L}^{-1}\right)$ & 0,00 & 0,17 & 0,03 & $\pm 0,03$ & 0,00 & 0,14 & 0,06 & $\pm 0,05$ & 1,00 & 1,00 & 1,00 \\
\hline Nitrato $\left(\mu \mathrm{mol} . \mathrm{L}^{-1}\right)$ & 0,00 & 3,29 & 0,82 & $\pm 0,80$ & 0,15 & 2,75 & 1,29 & $\pm 0,63$ & 0,06 & 0,05 & 0,26 \\
\hline Fosfato $\left(\mu \mathrm{mol} . \mathrm{L}^{-1}\right)$ & 0,00 & 0,15 & 0.06 & $\pm 0,04$ & 0,04 & 0,22 & 0,13 & $\pm 0,04$ & 1.00 & 1.00 & 1.00 \\
\hline Silicato $\left(\mu \mathrm{mol} . \mathrm{L}^{-1}\right)$ & 11,71 & 59,79 & 28,99 & $\pm 13,33$ & 12,84 & 92,26 & 38,19 & $\pm 23,96$ & 0,00 & 0,23 & 0,00 \\
\hline $\mathrm{pH}$ & 8,06 & 8,86 & 8,52 & $\pm 0,25$ & 7,15 & 8,95 & 8,35 & $\pm 0,47$ & 0,26 & 0,00 & 0,00 \\
\hline Biomassa Fitoplanctônica $\left(\mathrm{mg} \mathrm{m}^{-3}\right.$ ) & 1,29 & 11,05 & 3,48 & $\pm 2,15$ & 1,11 & 18,72 & 6,11 & $\pm 4,67$ & 0,00 & 0,09 & 0,00 \\
\hline Produtividade Primária $\left(\mathrm{mgC} \cdot \mathrm{m}^{-3} \cdot \mathrm{h}^{-1}\right)$ & 4,62 & 29,13 & 18,86 & $\pm 6,33$ & 9,67 & 75,27 & 32,84 & $\pm 18,57$ & 0,03 & 0,04 & - \\
\hline Taxa de Assimilação & 1,82 & 7,16 & 4,15 & $\pm 1,68$ & 0,86 & 7,41 & 4,57 & $\pm 2,50$ & 0,69 & 0,21 & - \\
\hline
\end{tabular}



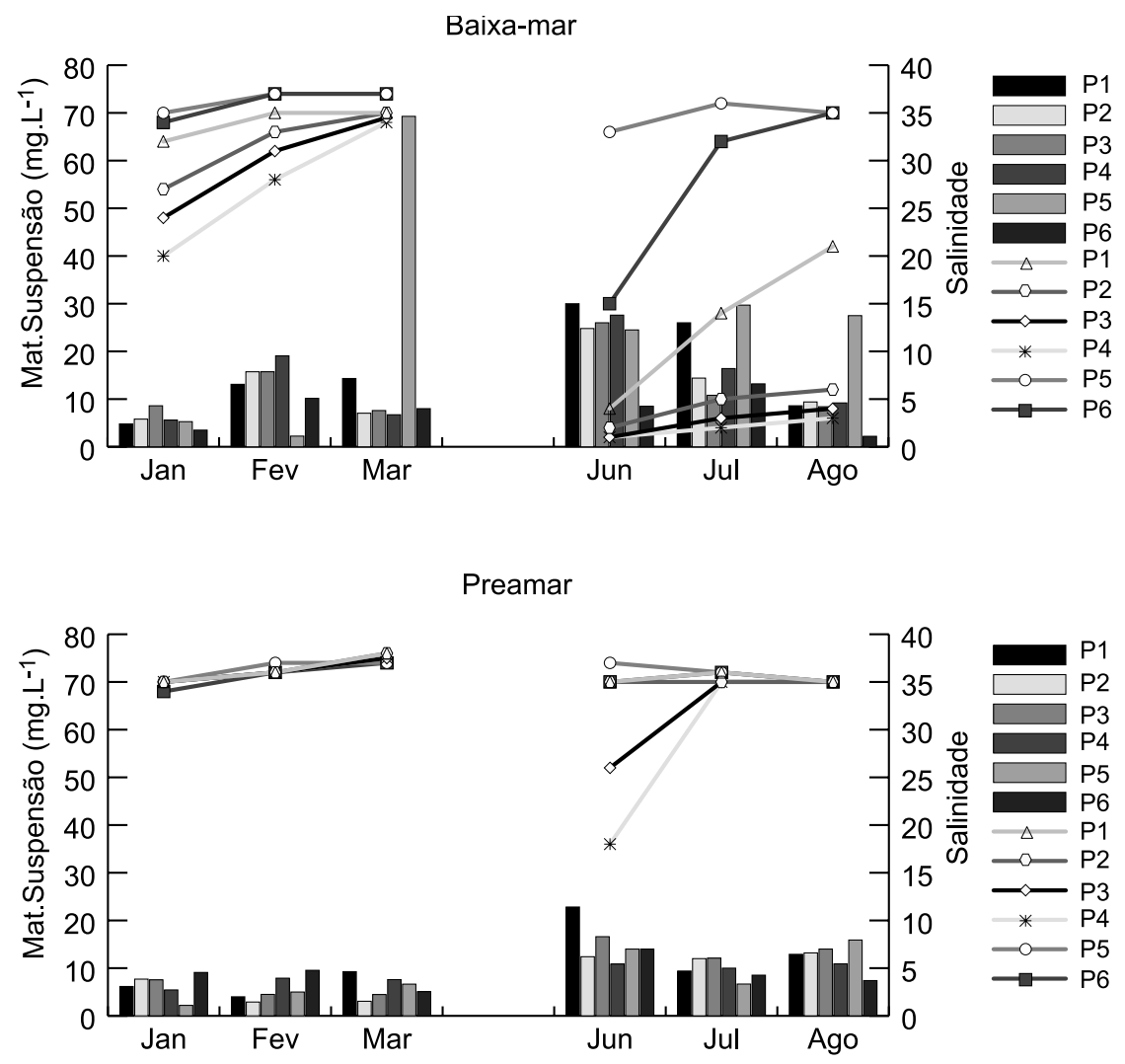

Figura 2 - Material particulado em suspensão (Barras) e salinidade (Linhas) na zona costeira de Maracaípe, PE, Brasil, nos períodos de estiagem e chuvoso e diferentes estágios de maré.

peratura mínima mensurada foi de $26,0^{\circ} \mathrm{C}$, em vários meses, estações e estágios de maré, e a máxima foi de $31,5^{\circ} \mathrm{C}$ no ponto 6 em março na baixa-mar (Tabela 1).

O ambiente variou de oligohalino a euhalino, observou-se um gradiente crescente de salinidade no período seco, do mês de janeiro a março. Espacialmente foi observado um gradiente decrescente dos pontos 1 para o 4, na baixa-mar, enquanto na preamar só no mês de junho ocorreu diferenças nos pontos 3 e 4 . A salinidade mínima obtida foi de 1 nos pontos 3 e 4 em junho na baixa-mar e a máxima foi de 37 nos pontos 1 e 2 em março na preamar (Tabela 1 e Figura 2).

O oxigênio dissolvido variou de $3,14 \mathrm{ml} . \mathrm{L}^{-1}$ no ponto 4 em agosto, durante a baixa-mar a $7,37 \mathrm{ml}^{-\mathrm{L}^{-1}}$ no ponto 6 , em fevereiro, na baixa-mar. Houve variação espacial com gradiente decrescente do ponto 1 para o 4, na baixa-mar no período de estiagem (Tabela 1), os pontos 5 e 6 (recifais) mostraram-se mais oxigenados. $\mathrm{Na}$ preamar os teores de oxigênio estiveram com concentrações semelhantes exceto para o ponto 4 em junho e 1 em julho.

Em relação à porcentagem de saturação a mínima foi de $56,78 \%$ no ponto 4 em agosto, na baixa-mar, e a máxima de $173,82 \%$ no ponto 6 , em fevereiro, durante a baixa-mar (Tabela 1 e Figura 2). No período chu- voso houve redução da taxa de saturação. O ambiente estudado variou de saturação normal até supersaturado, sendo que os pontos recifais estiveram sempre supersaturados.

O material particulado em suspensão variou de $2,20 \mathrm{mg} \cdot \mathrm{L}^{-1}$ no ponto $6 \mathrm{em}$ agosto na baixa-mar e no ponto 5 , em janeiro, na preamar, a $69,28 \mathrm{mg} \mathrm{L}^{-1}$ no ponto 5, em março, na baixa-mar (Tabela 1). Houve variação sazonal com teores mais elevados no período chuvoso, tanto na baixa-mar como na preamar. Levando em conta os diferentes estágios de maré, foi na baixamar onde se obteve maiores concentrações. Do ponto de vista espacial observaram-se variações, sendo que no período de estiagem, e nos meses de janeiro e fevereiro, houve certo gradiente crescente do ponto 1 para o 3 e que no mês de março os pontos 1 e 5 se destacaram dentre os demais. No período chuvoso não se observou gradientes, e sim diferenças entre os pontos, sendo que o ponto 5 se destacou na baixa-mar (Figura 2).

O nitrito apresentou baixos teores durante todo o período estudado, variando de indetectáveis, em vários pontos, meses, e estágios de maré a $0,17 \mu \mathrm{mol}^{-L^{-1}}$ no ponto 2 em junho na preamar (Tabela 1). Seus teores oscilaram muito espacialmente, porém mostrou tendência a maiores concentrações no período chuvoso, 


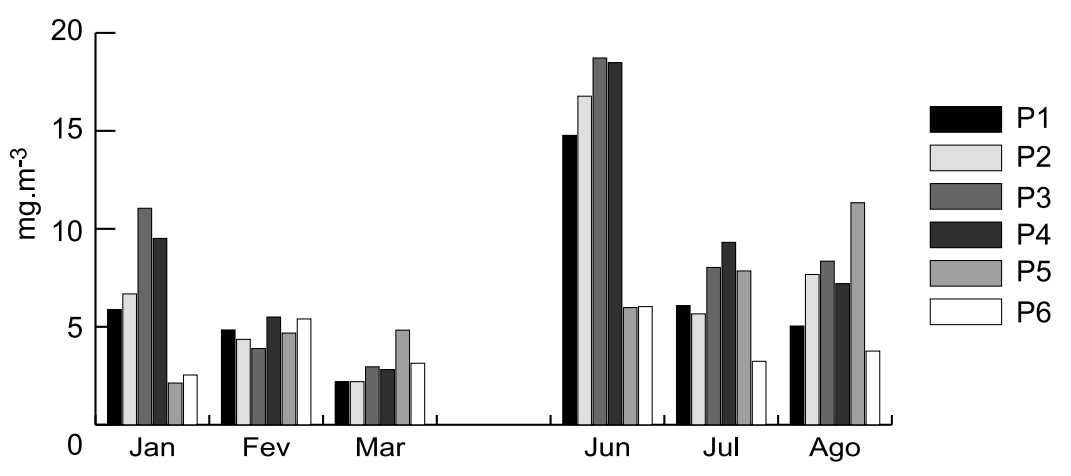

Preamar

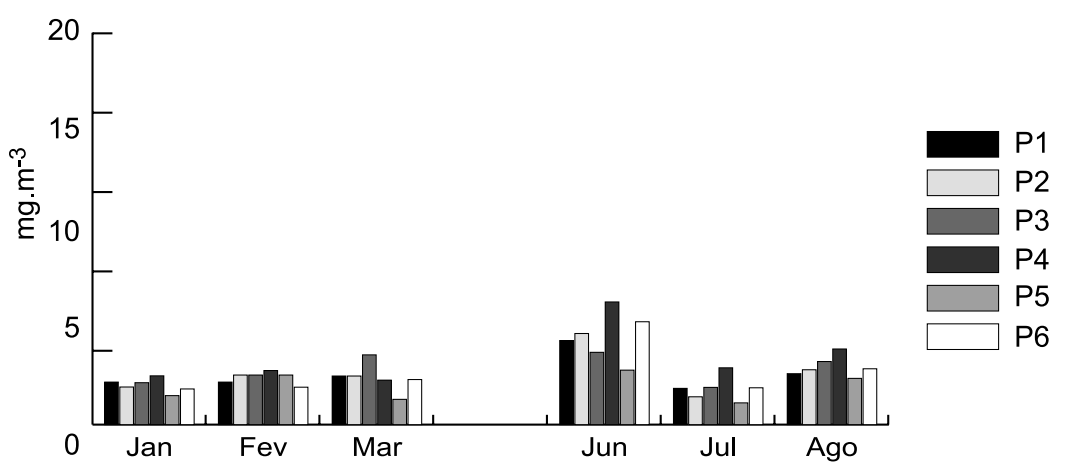

Figura 3 - Biomassa fitoplanctônica (Clorofila a) na zona costeira de Maracaípe, PE, Brasil, nos períodos de estiagem e chuvoso e diferentes estágios de maré.

em ambos estágios de maré, sendo maiores na preamar. Os teores de nitrito indicaram águas limpas, isentas de poluição orgânica.

O nitrato apresentou concentrações, baixas típicas de um ambiente sem grandes impactos, os teores variaram de indetectáveis no ponto 3 , em janeiro, a 3,29 $\mu \mathrm{mol} . \mathrm{L}^{-1}$ no ponto 4 em fevereiro (ambos durante a baixa-mar) (Tabela 1). Não houve nítida variação sazonal, e seus teores oscilaram entre os diferentes pontos de coleta.

Os teores de fosfato variaram de indetectáveis no ponto 5 e 6 em fevereiro na baixa-mar a $0,22 \mu \mathrm{mol}$.L ${ }^{1}$ no ponto 4 em junho na baixa-mar (Tabela 1 ). De forma geral os teores de fosfato estiveram baixos, em se tratando de um ambiente estuarino, o que mais uma vez confirma tratar-se de um ambiente ainda livre de poluição orgânica. Sazonalmente, as concentrações do fosfato aumentaram no período chuvoso em ambos os estágios de maré, e não se verificou nenhum gradiente entre as estações.

Os teores de silicato variaram de $11,71 \mu \mathrm{mol} . \mathrm{L}^{-1}$ no ponto 2 , em janeiro, durante a preamar, a $92,26 \mu \mathrm{mol} . \mathrm{L}^{-1}$ no ponto 2, em junho, na baixa-mar (Tabela 1). Sazonalmente, só foram encontradas variações nítidas entre os períodos de estiagem e chuvoso na baixa-mar, com maiores concentrações no período chu- voso, devido ao maior aporte fluvial. Apresentou-se uma correlação direta com o material particulado em suspensão, biomassa, produtividade e taxa de assimilação e inversa com a maré, profundidade, transparência, salinidade e oxigênio dissolvido.

$\mathrm{O} \mathrm{pH}$ da água esteve sempre alcalino com tendência a diminuir um pouco nos pontos 3 e 4 (estuarinos), no período chuvoso sendo na preamar sempre superior a 8,0. O mínimo obtido foi de 7,15 em agosto no ponto 3, na baixa-mar, e o máximo de 8,95, em julho, no ponto 6, na preamar (Tabela 1).

A concentração de clorofila a variou de $1,11 \mathrm{mg} \cdot \mathrm{m}$ ${ }^{3}$ no ponto 5 em julho na preamar a $18,72 \mathrm{mg}^{-3}{ }^{-3}$, no ponto 3 , em junho, durante a baixa-mar (Figura 3). 0 teor de clorofila a foi característico de um ecossistema costeiro, que se apresenta sem influência de poluentes domésticos e/ou industriais (Smith et al, 1999). Percebeu-se uma nítida variação sazonal, com teores mais elevados no período chuvoso e na baixa-mar, e um gradiente crescente do ponto 1 para o 3 nos meses de janeiro e junho. Dentre os pontos amostrados, o ponto 3 (estuarino) se destacou um pouco mais que os demais, e na área recifal o ponto 5 destacou-se por ter mostrado um gradiente crescente tanto no período de estiagem como no chuvoso durante a baixa-mar. $\mathrm{Na}$ preamar os teores de clorofila são parecidos, tanto es- 


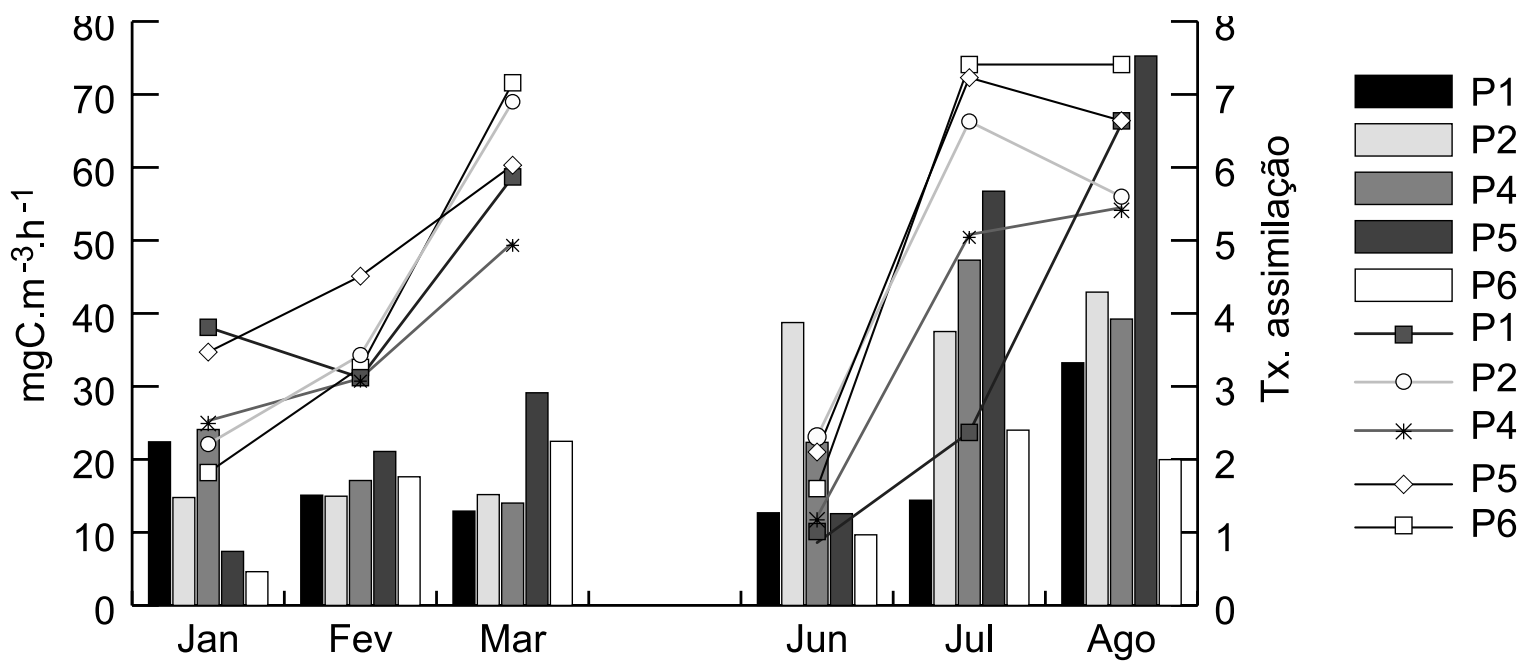

Figura 4 - Produtividade Fitoplanctônica (Barras) e taxa de assimilação (Linhas) nos períodos de estiagem e chuvoso na zona costeira de Maracaípe, PE, Brasil.

pacial como sazonalmente, exceto em junho, quando houve um discreto aumento em relação aos diferentes estágios de maré e verificou-se uma forte diferença desses teores com a baixa-mar, sendo bem superiores a preamar.

A produtividade variou de 4,62 no ponto 6 , em janeiro, a $75,27 \mathrm{mgC} \cdot \mathrm{m}^{-3} \cdot \mathrm{h}^{-1}$ no ponto 5 , em agosto (Figura 4). Foi observada uma nítida variação sazonal com maiores valores no período chuvoso. Espacialmente, verificou-se que os pontos recifais apresentaram maior produtividade, tanto no período de estiagem como no chuvoso, porém o ponto 5 foi mais evidenciado. Percebeu-se, entretanto, que os pontos estuarinos não demonstraram presença de gradientes entre eles, enquanto os recifais apresentaram gradiente crescente tanto no período de estiagem como no chuvoso. Dentre os diferentes pontos amostrados destaque maior se faz para o ponto 2 (estuarino) e o 5 (recifal).

A taxa de assimilação do fitoplâncton variou de 0,86 no ponto 1 , em junho a 7,41 no ponto 6 em julho e agosto (Figura 4). Observou-se um gradiente crescente em todas as estações de coleta nos dois períodos (estiagem e chuvoso). Baseado no sistema de classificação de Vollenweider et al. (1974), o ambiente estudado variou de oligotrófico a eutrófico, prevalecendo à condição de mesotrófico.

As duas primeiras componentes da ACP explicaram $60,24 \%$ das variações dos dados, sendo que a componente 1 explicou 38,55\% correlacionando diretamente altura de maré, profundidade local, transparência da água, salinidade, concentração e taxa de saturação do oxigênio dissolvido e inversamente com material particulado em suspensão, silicato, biomassa fitoplanctônica, produtividade primária e taxa de assimilação; já a componente 2 explicou 21,69\% relacionando diretamente a pluviosidade com o nitrito, nitrato e o fosfato e inversamente com a temperatura. Na com- ponente 1 destaca-se a maré como fator condicionante e na componente 2 a pluviosidade, o que já é padrão para zonas costeiras. Os dados foram considerados bem ajustados com o $r=0,83$. Foi evidenciado três grupos, o grupo 1 ficou representado pela maré, profundidade, transparência, salinidade, concentração e taxa de saturação do oxigênio; o grupo 2 associou a pluviosidade, o nitrito, nitrato e fosfato e o grupo 3 foi representado pela material particulado em suspensão, silicato, biomassa fitoplanctônica, produtividade primária e taxa de assimilação (Figura 5).

De acordo com o teste estatístico de KruskallWalis os parâmetros que apresentaram diferenças significativas em relação à sazonalidade, espacialidade e entre marés foram: salinidade, concentração e taxa de saturação do oxigênio dissolvido. A transparência da água, material particulado em suspensão, silicato e biomassa fitoplanctônica apresentaram diferenças significativas apenas para a sazonalidade e estágios de maré. $\mathrm{O}$ pH apresentou variação espacial e entre marés; a profundidade foi diferente significativamente apenas entre marés; a temperatura sazonalmente e a produtividade primária sazonalmente e espacialmente (Tabela 1).

\section{DISCUSSÃO}

A eutrofização é um sério problema ambiental e econômico nos ecossistemas costeiros do mundo e por isso tem sido recomendadas medidas de produtividade primária como um indicador acurado de alta sensibilidade para o monitoramento e acesso as condições ambientais dessas áreas (Smith, 2007).

A precipitação pluviométrica contribui de forma considerável no transporte de substâncias do continente 
para a zona costeira influenciando a produtividade primária.

De acordo com Noriega et al. (2009) as análises estatísticas determinaram diferenças significativas entre os períodos estudados (estiagem e chuvoso) demonstrando a grande influência e variabilidades da maré e descarga fluvial nos processos estuarinos tropicais.

Em Maracaípe a chuva foi significativa para influenciar a zona costeira, mostrando uma correlação direta com os sais nutrientes (nitrito, nitrato e fosfato). Este padrão também foi observado em outras áreas do nordeste brasileiro, como em Jaguaribe (PE) por Santos et al. (2000), no complexo lagunar estuarino Mundaú/ Manguaba (AL) por Melo-Magalhães et al. (2004), e no ecossistema recifal de Maracajaú (RN) por Feitosa \& Bastos (2007) e Mayal et al. (2009).

O ambiente estudado caracterizou-se por apresentar águas transparentes e baixa profundidade, ocorrendo a entrada dos sais nutrientes através do aporte fluvial, do aporte marinho e revolvimento do sedimento devido à baixa profundidade local. De acordo com Diehl (2002) em sistemas abertos ocorre uma relação direta entre a biomassa fitoplanctônica e ambientes extremamente rasos onde não há a reciclagem dos nutrientes sedimentados e sim um aporte desses nutrientes de áreas adjacentes. Outras áreas também já apresentaram condições semelhantes como o estuário dos rios Ilhetas e Mamucaba (PE), estudado por Losada et al. (2003), e o ambiente recifal de Porto de Galinhas (PE) por Fonseca et al. (2002) e Machado et al. (2007).

Segundo Passavante \& Feitosa (2004), a temperatura possui pouca variação em regiões tropicais podendo aparentar uma discreta influência em organis- mos fitoplanctônicos, porém seu efeito sinergético com outros parâmetros ambientais é de importância para o fitoplâncton. Nestas áreas a amplitude térmica é baixa, entretanto em Maracaípe foi observada uma diferença significativa em relação à sazonalidade tendo uma relação inversa com o aumento da biomassa fitoplanctônica, aporte dos sais nutrientes e material particulado em suspensão no período chuvoso. $\mathrm{O}$ ambiente não apresentou estratificação térmica, tendo o ponto 6 como destaque devido a sua lâmina d'água ser bastante reduzida em baixa-mar, o que elevou a temperatura.

A salinidade é um dos parâmetros que pode influenciar a produção primária, sendo esta influência mais restrita a áreas estuarinas que tem marcadas diferenças sazonais e diurnas. Tais oscilações são devidas a variação das marés e ao maior aporte de água doce e drenagem terrestre no período chuvoso (Passavante \& Feitosa, 2004). O ambiente estudado variou de oligohalino a euhalino, sendo típico de uma área estuarina, não apresentando estratificação salina, ocorrendo diferenças significativas em relação à sazonalidade, espacialidade e estágios de maré e uma relação inversa com a biomassa fitoplanctônica.

De acordo com Flores-Montes (1996) e Gardner et al. (2006), o oxigênio é um gás essencial para os organismos e um excelente indicador das condições ambientais, e o seu ciclo no ecossistema aquático é governado por vários processos bióticos e abióticos que produzem ou consomem o oxigênio dissolvido, como respiração, fotossíntese, oxidação da matéria orgânica e compostos químicos e processos metabólicos celulares.

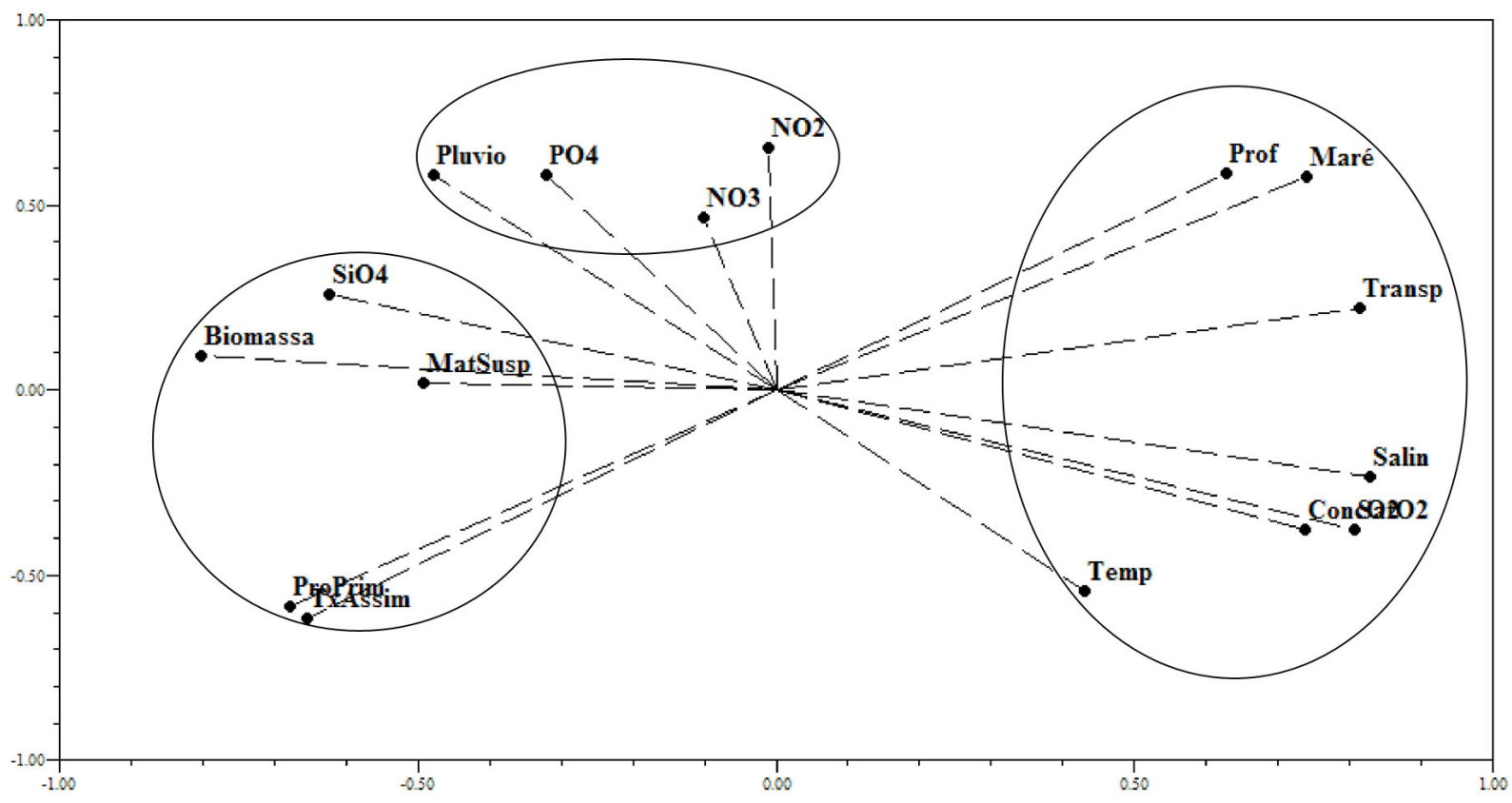

Figura 5 - Gráfico para as duas primeiras componentes principais para as variáveis analisadas. 
Maracaípe caracterizou-se por apresentar águas bem oxigenadas em função da baixa contribuição de matéria orgânica oriundas de ação antrópica e da marcante presença de organismos fotossintetizantes (macroalgas e zooxantelas), fato este também observado em outras áreas recifais como Maracajaú (RN) por Feitosa e Bastos (2007) e Porto de Galinhas (PE) por Machado et al. (2007). Levando em consideração a classificação de Macêdo \& Costa (1978), a taxa de saturação do oxigênio variou de saturação normal a supersaturado, sendo indicativo de uma área livre de poluição orgânica.

Por outro lado, o material particulado em suspensão foi típico de um rio considerado litorâneo, ou seja, com baixa contribuição para a zona costeira. A sua concentração esteve diretamente a biomassa fitoplanctônica. Os valores encontrados são compatíveis com outras áreas costeiras do nordeste brasileiro como encontrados por Machado et al. (2007) em Porto de Galinhas (PE) e por Feitosa \& Bastos (2007) em Maracajaú (RN).

Segundo Braga et al. (2000) e Pereira Filho et al. (2001), os sistemas estuarinos são os principais fornecedores de nutrientes para a região costeira, pois recebem e concentram o material originado de sua bacia de drenagem e podem vir a receber aportes significativos por ação antrópica. Colocando assim, os estuários como uma das regiões mais produtivas do mundo.

De acordo com Macêdo et al. (2004), os sais nutrientes possuem elevada importância no meio aquático, pois suas concentrações, juntamente com a luz, são os principais fatores limitantes da produção dos organismos clorofilados, interferindo assim em toda teia trófica.

Os teores de sais nutrientes foram baixos e característicos de um ambiente ainda isento de poluição orgânica. Este fato deve estar diretamente associado à condição de ser o rio Maracaípe um rio litorâneo e que não vem sofrendo fortes descargas de efluentes domésticos. Os teores variaram sazonalmente com aumento no período chuvoso. Sendo este padrão compatível com o encontrado por Losada et al. (2003) nos rios llhetas e Mamucaba que também são tidos como rios litorâneos e que sofrem baixa ação antrópica e diferentemente do encontrado por Noriega et al. (2009) no sistema estuarino de Barra das Jangadas onde os autores verificaram teores indicativos de poluição antrópica.

A eutrofização está diretamente relacionada à entrada e aos efeitos dos sais nutrientes nos sistemas aquáticos, e tem sido considerada uma das principais ameaças para a saúde dos ecossistemas marinhos, e por isso as medições de nutrientes e clorofila a são obrigatórias em órgãos governamentais e ambientalistas europeus como por exemplo o HELCOM e OSPAR (Andersen et al., 2006).
Os teores de clorofila a no ecossistema de Maracaípe foram típicos de áreas costeiras, que não sofrem com o lançamento de efluentes domésticos ou industriais no local. Estatisticamente, foi observada uma diferença significativa sazonal e tidal, com maiores valores no período chuvoso e durante a baixa-mar, mostrando uma alta correlação direta com o silicato, material particulado em suspensão, produtividade primária e taxa de assimilação evidenciando dessa forma a influência continental através do fluxo limnético.

Os valores encontrados em Maracaípe estiveram um pouco mais concentrados do que os obtidos em áreas recifais como nas águas costeiras da grande barreira de corais da Austrália por Furnas et al. (1990), na baía de Longoni, pertencente ao arquipélago de Comoro no oceano Índico por Vacelet et al. (1999), em Porto de Galinhas-PE por Machado et al. (2007) e nos parrachos de Maracajaú-RN por Feitosa \& Bastos (2007) e áreas estuarinas consideradas livre de poluição orgânica como o Estuário do rio Amazonas - AM por Santos et al. (2008) e o estuário do rio Una - PE por Bastos et al. (2005) e bem abaixo dos valores encontrados em estuários fortemente impactados como o sistema estuarino de Barra das Jangadas - PE por Branco (2007).

Os índices de produtividade primária foram típicos de uma área costeira considerada despoluída, elevando os seus valores no período chuvoso em conseqüência do maior fluxo limnético e maior aporte dos sais nutrientes, conforme o obtido para a clorofila a. $\mathrm{O}$ fato do ponto 5 (recifal) se destacar dos demais deve estar relacionado diretamente ao deslocamento da pluma do rio Maracaípe em direção norte devido aos ventos sudeste carreando uma maior quantidade de sais nutrientes para este ponto.

Ao compararmos os resultados da produtividade fitoplanctônica no ecossistema costeiro de Maracaípe com o recifal de Porto de Galinhas-PE (Machado et al., 2007) e Parrachos de Maracajaú-RN (Feitosa \& Bastos, 2007), que são áreas consideradas despoluídas e que sofrem influência continental, verifica-se que há o mesmo padrão sazonal com elevação da produtividade no período chuvoso, porém, os valores obtidos em Maracaípe foram superiores aos demais. Os dados obtidos para Maracaípe são compatíveis com os encontrados para outros rios litorâneos da região como o estuário do rio Jaguaribe(PE) estudado por Santos et al. (2000).

Do ponto de vista da taxa de assimilação, o ambiente variou de oligotrófico a eutrófico segundo a classificação de Curl \& Small (1965) e Vollenweider et al. (1974) onde ambientes com valores entre 0 - 3 são considerados como oligotróficos; entre 3 - 5 são mesotróficos e acima de 5 como eutróficos. 
Portanto, pode se concluir que a zona costeira de Maracaípe caracterizou-se por apresentar águas transparentes, mornas e de baixa profundidade, isenta de poluição orgânica e com índice de área mesotrófica. Percebeu-se ainda, uma intrusão (interferência) do ambiente estuarino sobre o recifal, havendo transporte de material particulado em suspensão e sais nutrientes, levando a um enriquecimento deste último.

\section{REFERÊNCIAS}

Andersen, J.P.; Schlüter, L.; ÆErtebjerg, G. 2006. Coastal eutrophication: recent developments in definitions an implications for monitoring estrategies. Journal of Plankton Research. 28 (7): 621-628.

Andrade, G.T.C.; Passavante, J.Z.O.; Muniz, K. 2004. Biomassa Fitoplanctônica do estuário do rio Maracaípe (Ipojuca, Pernambuco). In: Chellappa, N.T.; Chellappa, S.; Passavante, J.Z.O. (Eds.) Ecologia Aquática Tropical, Natal, 121-142 p.

Bastos, R.B.; Feitosa, F.A.N.; Muniz, K. 2005. Variabilidade espaço-temporal da biomassa fitoplanctônica e hidrologia no estuário do rio Una (PernambucoBrasil). Tropical Oceanography, 33 (1): 1-18.

Braga, E.S.; Bonetti, C.V.D.H.; Burone, L; Bonetti FiIho, J. 2000. Eutrophication na bacterial pollution caused by industrial and domestic wastes at the Baixada Santista Estuarine System - Brazil. Mar. Poll. Bull., 40 (2): 165-173.

Branco, E.S. 2007. Influência das variáveis ambientais na comunidade fitoplanctônica estuarina. Editora Universitária UFPE, Recife. 266p.

Corson, W.H. 2002. Manual global de ecologia: o que você pode fazer a respeito da crise do meio ambiente. Augustus, São Paulo, 413p.

Costa, M.F.; Neumann-Leitão, S.; Souza-Santos, L. P. 2004. Bioindicadores da qualidade ambiental. In: Eskinazi-Leça, E.; Neumann-Leitão, S.; Costa, M.F. Oceanografia: Um Cenário Tropical.. Ed. Bagaço, UFPE, 319-352pp.

CPRH. 1998. Estudo da erosão marinha na região de Maracaípe - Ipojuca. CPRH. 99p.

CPRH. 2003. Diagnóstico Socioambiental do Litoral Sul de Pernambuco. CPRH. 87p.

Chaves, N.S. Mapeamento do quaternário costeiro ao Sul do Recife - PE (área 4 Porto de Galinhas a Guadalupe). 1991. Relatório de Graduação. Departamento de Geologia da Universidade Federal de Pernambuco. Recife, 82p.

Curl, Jr. \& Small, L.F. 1965. Variation photossintetic assimilation rarious in natural marine phytoplankton communities. Limnology and Oceanography, 10: 6775.
Diehl, S. 2002. Phytoplankton, light, and nutrients in a gradient of mixing depths: Theory. Ecology, 83 (2): 386-398.

Eskinazi-Leça, E.; Moura, A.N.M.; Silva-Cunha, M.G.G.; Koening, M.L. 2002. Microalgas marinhas do Estado de Pernambuco. In: Tabarelli, M.; Silva, J.M.C. (Eds.) Diagnóstico da biodiversidade de Pernambuco. SECTMA e Ed. Massangana, Recife, 79-96pp.

Feitosa, F.A.N.; Bastos, R.B. 2007. Produtividade fitoplanctõnica e hidrologia do ecossistema costeiro de Maracajaú - RN. Arq. Ciên. Mar, 40 (2): 2636.

Flores-Montes, M.J. 1996. Variação nictemeral do fitoplâncton e parâmetros hidrológicos no canal de Santa Cruz, Itamaracá, PE. Dissertação de Mestrado em Oceanografia. Universidade Federal de Pernambuco, Recife. $197 \mathrm{p}$.

Fonseca, R.S.; Passavante, J.Z.O.; Maranhão, G.M.B.; Muniz, K. 2002. Ecossistema recifal da praia de Porto de Galinhas (Ipojuca, Pernambuco): biomassa fitoplanctônica e hidrologia. Bol. Técn. Cient. CEPENE, 10 (1): 9-26.

Furnas, M.J.; Mitchell, A.W.; Gilmartin M.; Revelante, N. 1990. Phytoplankton biomass and primary production in semi-enclosed reef lagoons of the central Great Barrier Reel Australia. Coral Reefs, 9: 110.

Gardner, L.R.; Kjerve, B.; Petrecca, D.M. 2006. Tidal fluxes of dissolved oxygen at the North Inlet-Winyah Bay National Estuarine Research Reserve. Estuar. Coastal and Shelf Sci., 67: 450-460.

GESAMP (Joint group of expert on the scientific aspects of marine environmental protection). 1995. Biological indicators and their use in the measurement of the condiction of the marine environment. Report Studies, 55: 56p.

Grasshoff, K.; Ehrhardt, M.; Kremling, K. (Ed.). 1983. Methods of Seawater Analisys. $2^{-\underline{a}}$ edição. Verlag Chemie, 419p.

Legendre, L.; Legendre, P. 1984. Ecologie Numérique. 2 edição. Quebec: Masson Presses de L'Université du Quebec. v.1: Le traitement multiple dês données écologiques. (Collection d'écologie, 12). Masson Presses de L'Université Du Quebec. 2ªEd.

Losada, A.P.M; Feitosa, F.A.N.; Lins, I.C. 2003. Variação sazonal e espacial da biomassa fitoplanctônica nos estuários dos rios Ilhetas e Mamucaba (Tamandaré-PE) relacionada com parâmetros hidrológicos. Tropical Oceanography, 31 (1): 1-26.

Macêdo, S.J.; Costa, K.M.P. 1978. Estudo ecológico da região de Itamaracá Pernambuco -Brasil, condições hidrológicas do estuário do rio Botafogo. Ciência e Cultura. São Paulo, 30 (7): 368 p. 
Macêdo, S.J.; Muniz, K.; Flores-Montes, M.J. 2004. Hidrologia da região costeira e plataforma continental do Estado de Pernambuco. In: Eskinazi-Leça E.; Neumann-Leitão, S.; Costa, M. F. (Ed.). Oceanografia: Um cenário tropical. Recife: Bagaço. 255286pp.

Machado, R.C.A.; Feitosa, F.A.N.; Bastos, R.B.; Travassos, R.K. 2007. Dinâmica da biomassa fitoplanctônica e parâmetros hidrológicos no ecossistema recifal de Porto de Galinhas, Pernambuco, Brasil. Bol. Técn. Cient. CEPENE, 15 (2): 17-29.

Manso, V.A.V.; Corrêa, I.C.S.; Guerra, N.C. 2003. Morfologia e sedimentologia da plataforma continental interna entre as praias Porto de Galinhas e Campos - Litoral sul de Pernambuco, Brasil. Pesquisas em geociências. 30(2): 17-25.

Mayal, E.M.; Neumann-Leitão, S.; Feitosa, F.A.N.; Schawamborn, R.; Silva, T.A.; Silva-Cunha, M.G. 2009. Hydrology, plankton and corals of Maracajaú reefs (Northeastern Brazil) - an ecosystem under severe thermal stress. Braz. Arch. Biol. Technol., 52 (3): 665-678.

Melo, V.; Summerhayes, C.D. \& Toner, L.G. 1975. Metodologia para estudos do material em suspensão na água do mar. Boletim Técnico da Petrobrás, Rio de Janeiro, 18(314): 115-127.

Melo-Magalhães, E.M.; Koening, M.L.; Sant'Anna, C.L. 2004. Fitoplâncton e variáveis ambientais nos canais do sistema estuarino lagunar Mundaú/ Manguaba, Alagoas, Brasil. Hoehnea, 31 (1): 7386.

Nixon, S.W. 1995. Coastal marine eutrophication: a definition, social causes and future concerns. Ophelia. 41: 199-219.

Noriega, C.E.; Muniz, K.; Flores-Montes, M.J.; Macêdo, S.J.; Araújo, M.; Feitosa, F.A.N.; Lacerda, S.R. 2009. Series temporales de variables hidrobiológicas en un estuario tropical (Brasil). Revista de Biología Marina y Oceanografía, 44 (1): 93-108.

Passavante, J.Z.O.; Feitosa, F.A.N. 2004. Dinâmica da produtividade fitoplanctônica na zona costeira marinha. In: Eskinazi-Leça E.; Neumann-Leitão, S.; Costa, M. F. (Ed.) Oceanografia: Um cenário tropical. Recife: Bagaço. 425-439pp.

Pereira, R.C.; Soares-Gomes, A. 2002. Biologia Marinha. Ed. Interciência, Rio de Janeiro, 382p.

Pereira Filho, J.; Schettini, C.A.F.; Rörig, L.; Siegle, E. 2001. Intratidal variation and net transporto $f$ dissolved inorganic nutrients, POC and chlorophyll a in the Camboriú River Estuary, Brazil. Estuar. Coastal and Shelf Sci., 53: 249-257.

Santos, L.S.; Medeiros, C.; Muniz, K.; Feitosa, F.A.N.; Schwamborn, R.; Macêdo, S. 2008. Influence of the Amazon and Pará Rivers on water composition and phytoplankton biomass on the adjacent shelf. Journal of Coastal Ressearch, 24 (3): 585-593.

Santos, T.L.; Passavante, J.Z.O.; Koening, M.L.; Macedo, J.M.; Lins, I.C. 2000. Fitoplâncton do estuário do rio Jaguaribe, (Itamaracá, Pernambuco, Brasil): produção e hidrologia. Revta. Ecol. Aqua. Tropi., 10: 43-69.

Silva-Cunha, M.G.G. 2001. Estrutura e dinâmica da flora planctônica no canal de Santa Cruz - Itamaracá -Pernambuco - Nordeste do Brasil. Tese de Doutorado em Oceanografia Biológica. Departamento de Oceanografia, Universidade Federal de Pernambuco. Recife, PE. 246p.

Smith, V.H.; Tilaman, G.D., Xelaila, J.C. 1999. Eutrophication: Impacts of excess nutrient inputs on freshwater, marine and terrestrial ecosystems. Fisheries Bulletin. 100: 179-196.

Smith, V.H. 2007. Using primary productivity as an index of coastal eutrophication: the units of measurement matter. Journal of Plankton Research, 29 (1): 1-6.

Steemann-Nielsen, E. 1952. The use of radio-active carbon $\left(\mathrm{C}^{14}\right)$ for measuring organic production in the sea. Journal du Conseil Plemanent International Pour L Exploration de le Mer. Copenhague, 18 (2): 117-140.

Strickland, J.D.H.; Parsons, T.R.A. 1972. Practical handbook of sea water analysis. Bulletin Fisheries Research Board of Canada, Ottawa, 167: 207-211.

Teixeira, C. 1973. Introdução aos métodos para medir a produção primária do fitoplâncton marinho. Boletim Instituto Oceanográfico Universidade de São Paulo. São Paulo, 22(fasc. Único): 59-92.

UNESCO. 1966. Determination of photosyntetic pigments in sea water. Rapor of SCOR/UNESCO, working group 17 with meat from 4 to 6 June 1964 . monography on Oceanography Methodology, 1. Paris, 69p.

UNESCO. 1973. International Oceanographic Table. Great Britain Wormly, 2: 141p.

Vacelet, E.; Arnoux, A.; Thomassin, B.A.; Travers, M. 1999. Influence of freshwater and terrigenous material on nutrients, bacteria and phytoplankton in a high island lagoon: Mayotte, Comoro Archipelago, Indian Ocean. Hydrobilogia, 380: 165-178.

Vollenweider, R.A.; Talling, J.F.; Westlake, D.F. 1974. A manual in method for measuring primary production in aquatic environments, incluind a chapter on bacteria. International Biological Program Handbook, 2 edição, Oxford, 225p. 